\title{
In vitro skin three-dimensional models and their applications
}

\author{
Julia Klicks ${ }^{\mathrm{a}, 1}$, Elena von Molitor ${ }^{\mathrm{a}, 1}$, Torsten Ertongur-Fauth ${ }^{\mathrm{b}}$, Rüdiger Rudolf ${ }^{\mathrm{a}, \mathrm{c}, *}$ \\ and Mathias Hafner ${ }^{\mathrm{a}, \mathrm{c}, *}$ \\ a Mannheim University of Applied Sciences, Institute of Molecular and Cell Biology, \\ Mannheim, Germany \\ ${ }^{\mathrm{b}}$ BRAIN AG, Zwingenberg, Germany \\ ${ }^{\mathrm{c}}$ Institute of Medical Technology, Heidelberg University, Heidelberg, Germany
}

\begin{abstract}
Skin fulfils a plethora of eminent physiological functions ranging from physical barrier over immunity shield to the interface mediating social interaction. Prone to several acquired and inherited diseases, skin is therefore a major target of pharmaceutical and cosmetic research. The lack of similarity between human and animal skin and rising ethical concerns in the use of animal models have driven the search for novel realistic three-dimensional skin models. This review provides a survey of contemporary skin models and compares them in terms of applicability, reliability, cost and complexity.
\end{abstract}

Keywords: Skin, phenotypic screening, 3D models, pharmaceutical research

\section{Skin - composition and function}

Human skin covers an area of almost $2 \mathrm{~m}^{2}$ in the adult and consists of the three major layers, subcutis, dermis, and epidermis. The subcutis is composed of adipose and epithelial cells. It harbours blood vessels, neurites of peripheral neurons, Vater-Pacini mechanosensors, and, partially, also sweat glands and hair follicles. It connects the skin to periosteum and fascia, absorbs forces, and mediates thermal insulation. The dermis supplies the epidermis with mechanical support and nutrients. It is stratified into an inner, reticular, and an outer, papillary, zone. The dermis houses most sebaceous glands, sweat glands, hair follicles, smooth muscle cells, and capillary beds and, thus, regulates skin moisture, body temperature, and performs the secretory function of skin. The papillary layer is characterized by relatively loose connective tissue, where Meissner corpuscles sense touch. Immune cells, particularly mast cells and dendritic cells, are patrolling in the papillary layer and mediate local inflammatory reactions and immune surveillance. Finally, dermal fibroblasts secrete extracellular matrix (ECM) and basement membrane components. These are primarily collagens I and III, and a proteoglycan-rich ground substance [1]. The resulting ECM mediates tensile strength of the dermis. The dermo-epidermal junction is centered around a special basement membrane. This is composed of a laminin/collagen IV scaffold and further typical basement membrane components such as perlecans and nidogens [1].

The epidermis is a squamous epithelium of 50-100 $\mu \mathrm{m}$ thickness. It is devoid of blood vessels but contains keratinocytes, Merkel cell mechanosensors, Langerhans immune cells, and melanocytes. The

\footnotetext{
${ }^{1}$ These authors contributed equally.

${ }^{*}$ Corresponding authors. Rüdiger Rudolf and Mathias Hafner, Mannheim University of Applied Sciences, Institute of Molecular and Cell Biology, Paul-Wittsackstrasse 10, 68163 Mannheim, Germany. Tel.: +49 621 2926200; E-mails: r.rudolf@hs-mannheim.de (R. Rudolf), m.hafner@hs-mannheim.de (M. Hafner).
} 
Table 1

Marker molecules for the analysis of epidermal stratification

\begin{tabular}{|c|c|c|c|}
\hline Protein & Epidermal layer & Physiological function & Ref. \\
\hline KRT5/KRT14 & Stratum basale & Resilience & {$[2,95]$} \\
\hline KRT1/KRT10 & Stratum spinosum & Resilience, part of cornification & {$[2,95]$} \\
\hline KRT6/KRT16 & Activated keratinocytes & Resilience & [6] \\
\hline KRT17 & Contractile keratinocytes & $\begin{array}{l}\text { Resilience, regulation of protein } \\
\text { synthesis and cell size }\end{array}$ & {$[6,7,15]$} \\
\hline Involucrin & $\begin{array}{l}\text { Stratum spinosum, Stratum } \\
\text { granulosum, Stratum corneum }\end{array}$ & $\begin{array}{l}\text { Cornification of plasma membrane, } \\
\text { scaffold for other envelope proteins }\end{array}$ & {$[8,96]$} \\
\hline Loricrin & Stratum granulosum, Stratum corneum & Major cornified envelope component & {$[8,97]$} \\
\hline Profilaggrin & Stratum granulosum & Filaggrin precursor & {$[8,98,99]$} \\
\hline Filaggrin & Stratum corneum & Keratin crosslinking & {$[8,98,99]$} \\
\hline Ki67 & Stratum basale, Stratum spinosum & $\begin{array}{l}\text { Undefined role in cell division, rRNA } \\
\text { synthesis, maintenance of mitotic } \\
\text { spindle }\end{array}$ & {$[100-102]$} \\
\hline Cleaved caspase 3 & Stratum granulosum & Execution of apoptosis & {$[102-104]$} \\
\hline
\end{tabular}

epidermis shows two germinal layers (stratum basale and spinosum), a secretory layer (stratum granulosum), and a layer of dead cells aka corneocytes, and secreted lamellar bodies (stratum corneum). Thick skin on palms of hands and feet features an additional layer, stratum lucidum, between stratum granulosum and stratum corneum. Keratinocytes give ultimate strength to skin through intracellular intermediate filament systems made up of keratins, which connect to neighbouring cells via desmosomes containing desmoplakin and to the basement membrane via hemidesmosomes containing plectin [2]. For this reason, mutations in keratin genes $(K R T)$ lead to various threatening skin diseases, such as epidermolysis bullosa simplex, which is due to mutations in either KRT5 or KRT14 [3].

Epidermal keratinocytes progress from the basal to the cornified layers, allowing for the regeneration of epidermis within 60 days in an average adult [4]. Accordingly, keratinocyte gene expression undergoes robust longitudinal changes, which is particularly well understood and characterized for keratins [2, 5-7]. As outlined in Table 1, KRT5 and KRT14 are typical for basal keratinocytes, while KRT1 and KRT10 are increasingly expressed during differentiation and postmitotic stages. The switch from KRT5/14 to KRT1/10 occurs in a gradual transition process [2]. Therefore, a mixed composition of keratins can be observed in intermediate differentiation stages. The terminal differentiation of the waterrepellent and antibiotic stratum corneum happens in the stratum granulosum and stratum corneum [8]. It involves the release of lamellar bodies leading to an extracellular, highly-ordered lipid matrix that consists of ceramides, cholesterol, and fatty acids [9] and the intracellular aggregation of an envelope composed of keratins, involucrin, filaggrin, and loricrin $[4,8]$. The lipid matrix serves as a bedding for corneocytes and the proteinaceous envelope in corneocytes adds mechanical stability. Terminal differentiation of keratinocytes occurs in a temperature- and $\mathrm{Ca}^{2+}$-dependent manner $[4,10]$. Indeed, envelope formation is favoured in the presence of millimolar amounts of $\mathrm{Ca}^{2+}$ and lowered temperature $[4,10]$. Also, the secretion of lamellar bodies is preceded by $\mathrm{Ca}^{2+}$-influx into keratinocytes [4] and coincides with apoptotic cell death conversion from keratinocytes to corneocytes [11]. Conversely, cell proliferation in the basal layers necessitates low, micromolar $\mathrm{Ca}^{2+}$-levels. The phenotypic analysis of proliferation versus apoptosis in keratinocyte three-dimensional (3D) cultures is shown in Fig. 1. Due to the ambivalent function of $\mathrm{Ca}^{2+}$, a steep $\mathrm{Ca}^{2+}$-gradient needs to be maintained between inner and outer layers of the epidermis. Two principal mechanisms for its establishment are being discussed, i.e. the barrier function of the stratum corneum and the presence of tight junctions [12]. 

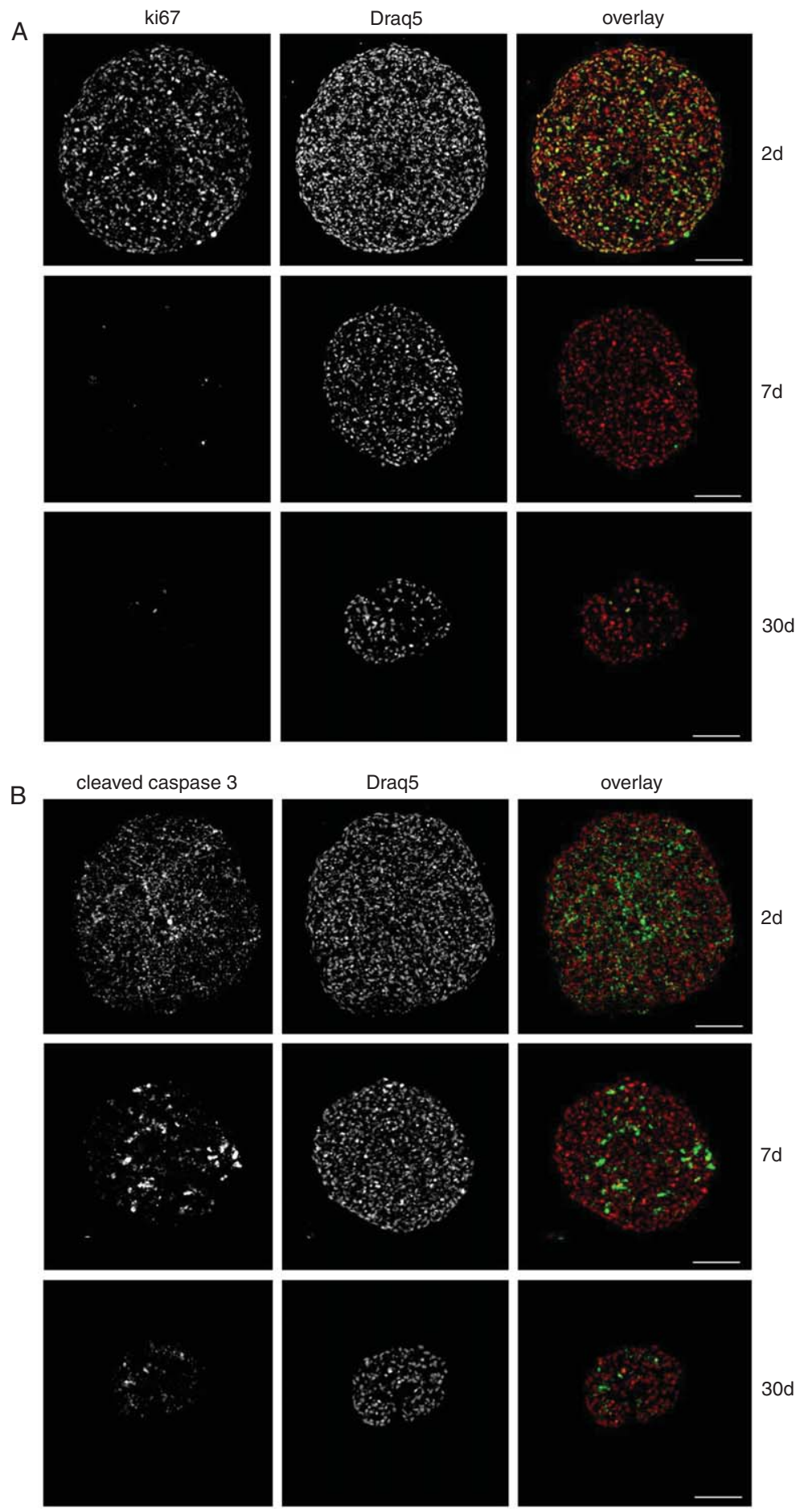

Fig. 1. Phenotypic analysis of HaCaT spheroids. HaCaT cells were grown as spheroids. After 2, 7, and 30 days, spheroids were sectioned into 10- $\mu \mathrm{m}$ thick slices and immunostained for Ki67 (A) or Cleaved caspase 3 (B), respectively. Nuclei were labeled with Draq5. Scale bars, $100 \mu \mathrm{m}$. Ki67 is a well-known marker to differentiate between dividing and postmitotic cells [102]. This is found within the nucleus during $G_{1}, S$ and $G_{2}$, while in mitosis it is bound to dividing chromosomes. At $G_{0}$ it is not present at all [100]. Caspase 3 is a major executioner caspase in all types of apoptosis. Its prodomain is cleaved upon apoptosis induction thereby activating its function that leads to the execution of apoptotic cell death [102, 104, 105]. 
The latter can be found at the stratum granulosum and serve as a major barrier of skin. Tight junction proteins claudin-4 and occludin can be found in that skin layer [13].

The differentiation from basal keratinocytes to shielding corneocytes occurs in normal, uninjured skin; but disturbance of this well-orchestrated process can be associated with chronic skin disorders such as atopic dermatitis and psoriasis. In psoriasis, inflammatory cytokines (e.g. TNF-alpha and IL-17) are secreted from immune cells, which trigger drastic gene expression changes ultimately leading to hyperproliferative, incompletely differentiated epidermal keratinocytes [14]. Such psoriatic keratinocytes show increased expression of hyperproliferative markers KRT6 and KRT16, downregulation of differentiation markers KRT1 and KRT10 as well as early onset of IVL expression. As a consequence, the psoriatic skin lesion is characterized by hyperplasia of the epidermis with excessive cornification but poorly adherent stratum corneum, which results in the psoriatic characteristic flakes [14].

In the case of acute skin lesions, keratinocytes undergo a different process, termed keratinocyte activation cycle [6]. Here, injured keratinocytes release IL-1, which triggers local blood vessel formation and immune response. Also, IL-1 switches keratinocytes to become proliferative and migratory, and to change gene expression. This upregulates the activated keratinocyte markers KRT6 and KRT16 (Table 1) and stimulates secretion of several paracrine factors. Activation is maintained by some of these signalling molecules and results in a release of chemoattractants for immune cells. The concerted action of keratinocytes, endothelial cells, and immune cells will eventually resolve the acute local inflammatory stimuli and allow a partial closure of the wound. Further healing involves the release by fibroblasts of a new basement membrane and its contraction by contractile keratinocytes [6, 15]. These express KRT17 (Table 1), and are transformed from activated keratinocytes by IFNgamma. Close to definitive wound healing, fibroblasts release TGF-beta, which shifts keratinocytes to the basal phenotype, i.e. suppressing hyperproliferation, activating the standard keratinocyte differentiation program, stimulating the production of ECM components, and inducing normal keratinocyte layering $[6,16]$. The critical role of enrichment of TGF-beta for sheeting behaviour was shown in a study comparing standard spheroid versus microbubble 3D cultures of keratinocytes [16]. While in the first, secreted molecules such as TGF-beta could diffuse freely, the compartmentation induced by the microbubble cultivation technique arguably led to a local increase in TGF-beta which induced a sheeting cell growth [16]. Using a similar chip-based technology featuring micro-fenestrated 300- $\mu \mathrm{m}$ wide compartments (KIT Chip), we could recently confirm these findings and show a regular layered expression of keratinocyte differentiation markers, KRT14 and KRT10 (Fig. 2).

\section{Skin - current in vitro test systems and which functions can be tested with these}

The important functions of skin make it a principal organ for body health and physiology. Accordingly, pharmacological and biomedical research necessitates appropriate test systems for finding novel drugs and treatments. The same is true for the development of new cosmetics, which have always been central to mankind. For both applications, though, animal models are not ideal. On the one hand, frequently used and relatively economic species such as rodents do have a skin composition that is too different to human skin to be comparable. On the other hand, animals with more human-like skin, such as pigs, are too difficult to manage and too expensive for regular use. On top, ethical reasons preclude this as well, rendering animal models for skin research less and less attractive. However, also two-dimensional (2D) skin cell cultures that have been used since decades now, come with an overt lack of physiological relevance. Most principal functions of skin, like barrier function, resilience, cell sheeting, cell layering, developmental profiles, immune function, blood perfusion, and innervation, are not recapitulated in simple 2D cultures. The following chapters introduce major 3D skin models used 


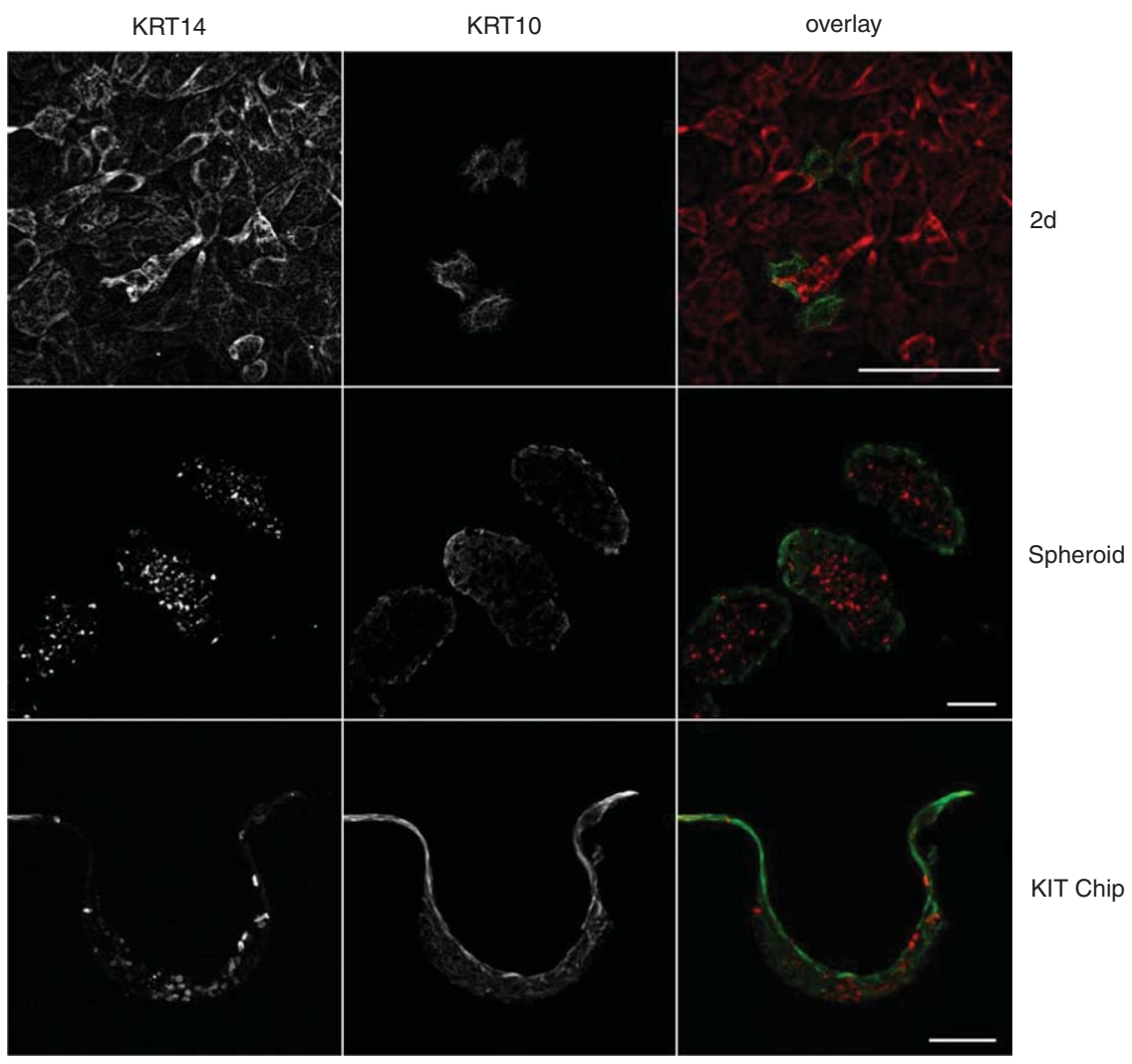

Fig. 2. Analysis of differentiation of HaCaT cells in 2D and 3D models. HaCaT cells were grown in 2D, as spheroids, and in a microbubble format (KIT Chip). KIT Chips were assembled as described previously [106]. After 7 days, spheroids were cryosectioned into $10-\mu \mathrm{m}$ slices and the KIT Chip was cut with a microtome. Samples were stained for KRT14 and KRT10 to mark basal cells and differentiated keratinocytes, respectively. Scale bars, $100 \mu \mathrm{m}$.

in research and drug discovery and briefly discuss their advantages and disadvantages. An overview of these models and their main applications in basic, toxicological, and pharmaceutical research is given in Table 2.

\subsection{Spheroids}

The observation, that malignant cells are more likely to aggregate than normal cells when cultured in an Erlenmeyer on a shaker [17] gave rise to the spheroid technology and its use in oncology research. Sutherland and colleagues termed their Chinese hamster V79 lung cell aggregates "multicellular spheroids" and further described the three typical zones found in most of these 3D spherical cultures: an inner necrotic layer, an intermediate zone of quiescent cells as well as an outer stratum of proliferating cells [18]. However, depending on the application, small spheroids can be generated to avoid a necrotic core [19]. Spheroids are mostly made by the hanging drop method [20, 21] or by the use of non-adherent U-bottom shaped plates [22]. Furthermore, some cells like melanocytes need the addition of a coating such as chitosan to form spheroids [23]. More recently, new methods have become commercially available that allow the aggregation of magnetised cells [24, 25].

Spheroids are not amongst the classical 3D models for skin research. Indeed, until now there have been only very view papers using HaCaT cells or fibroblasts co-cultured with melanoma cells in the spheroid format to gain tumour models. Okochi and colleagues investigated the interaction of 


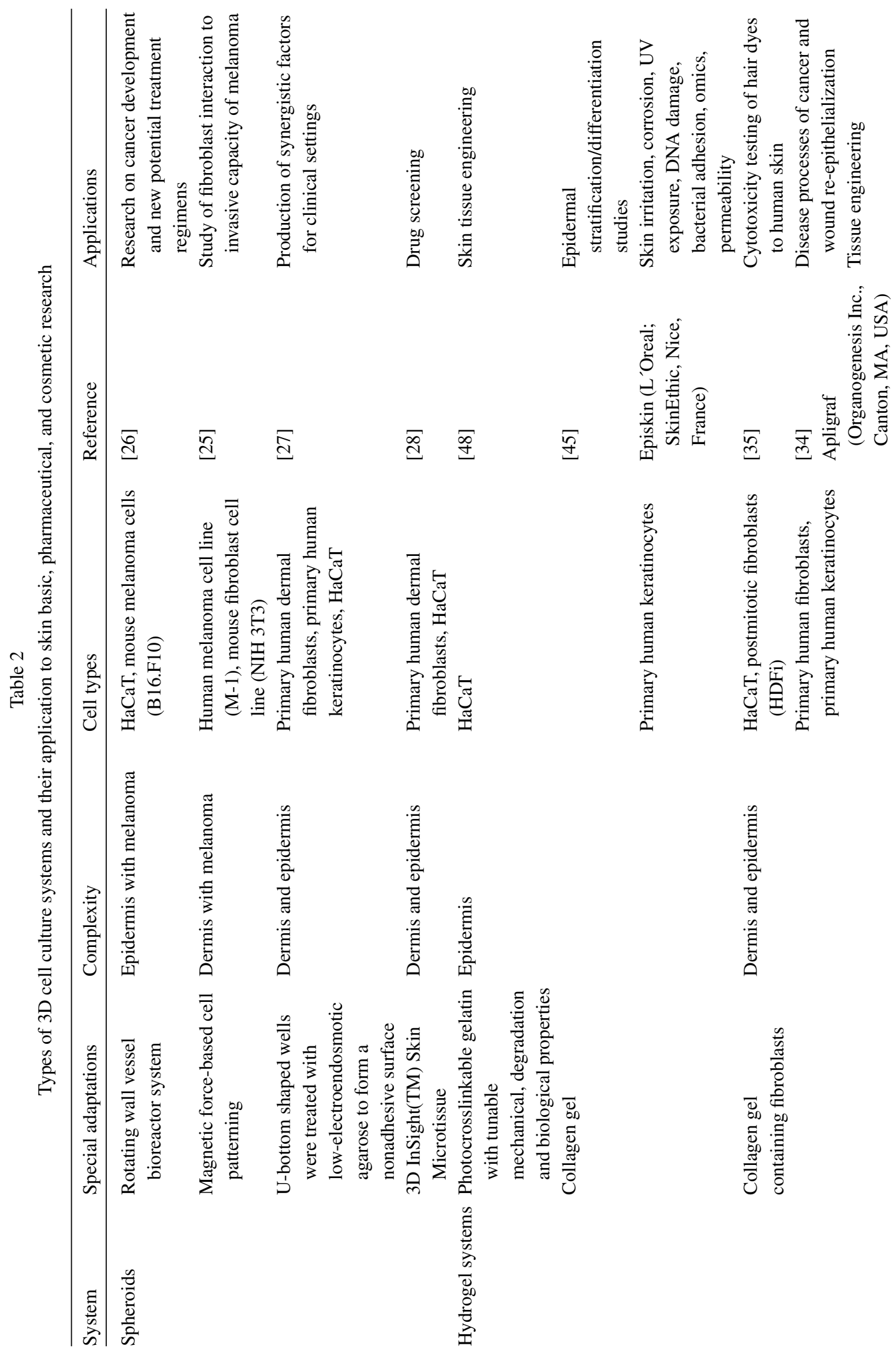



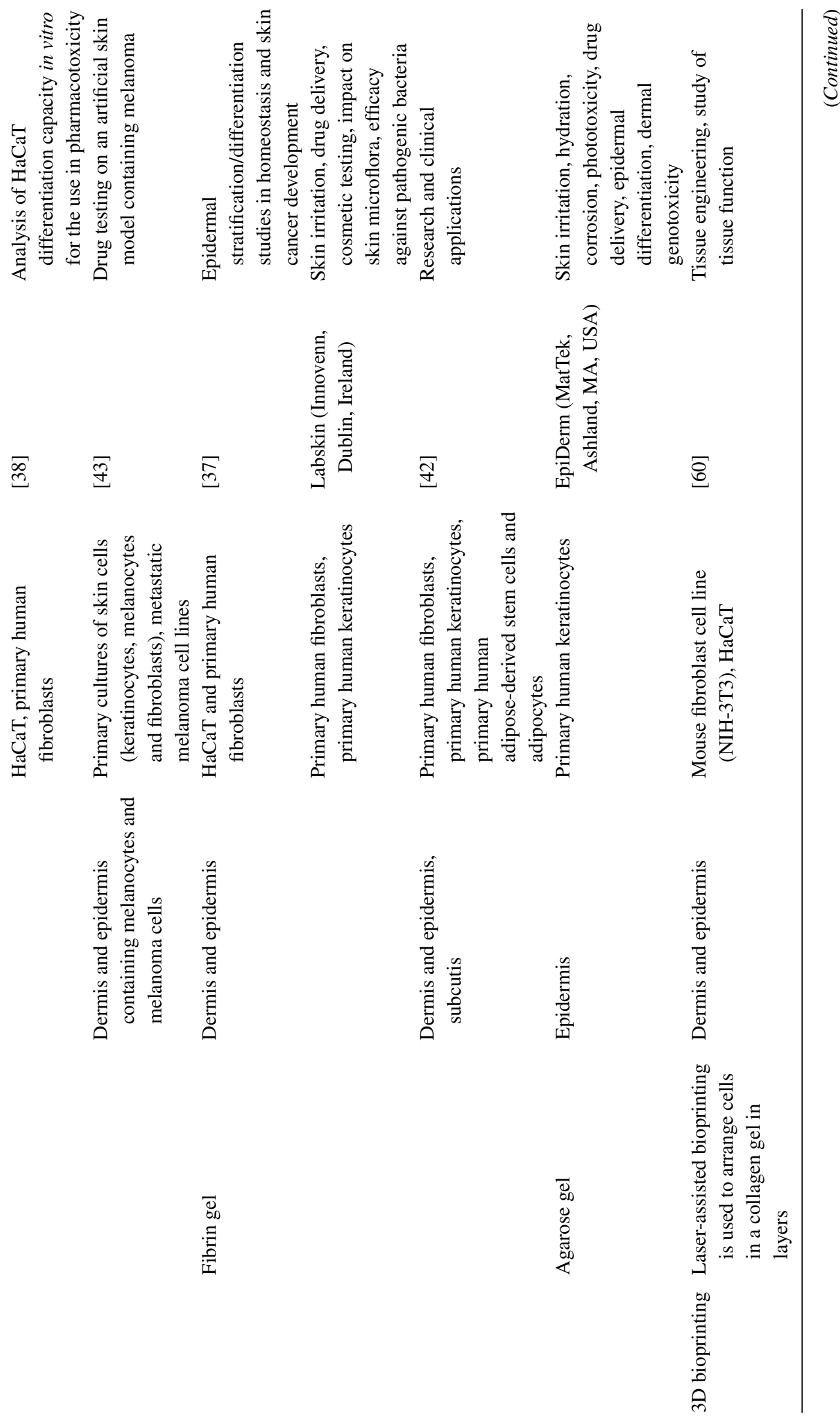

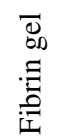

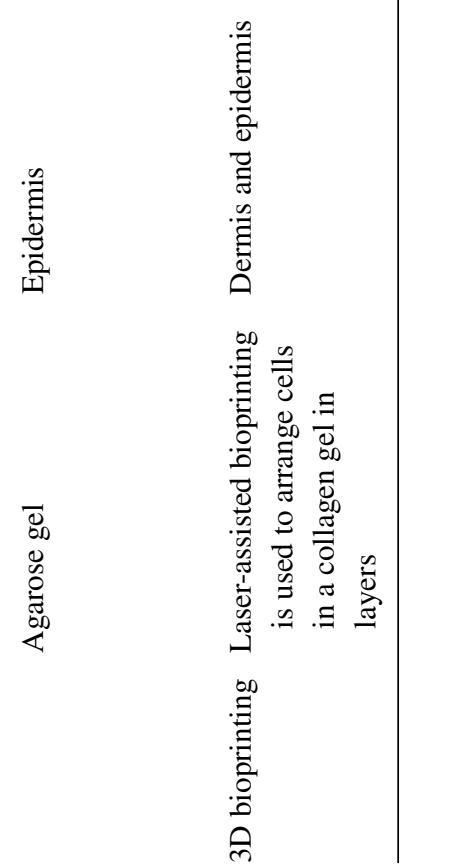




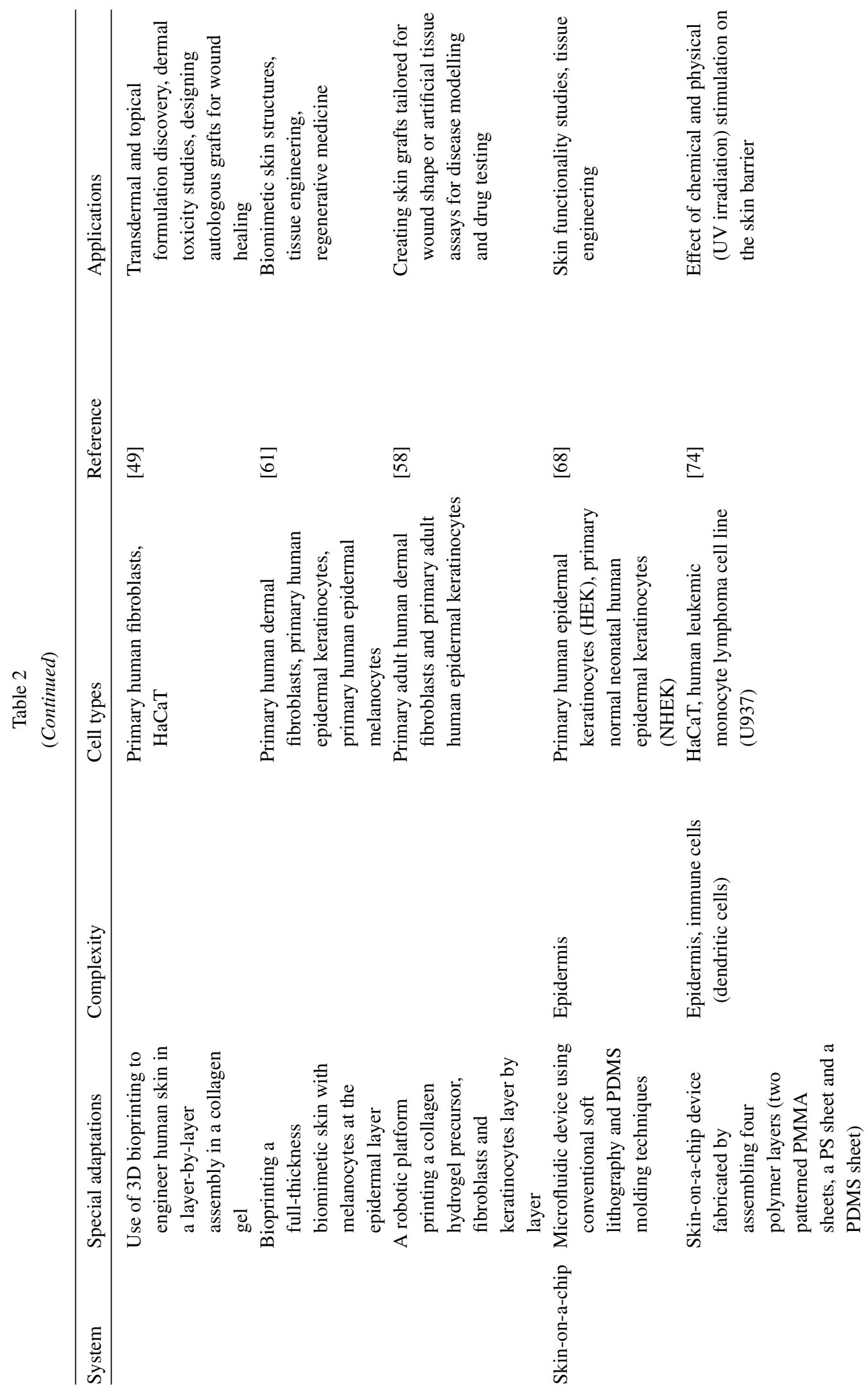



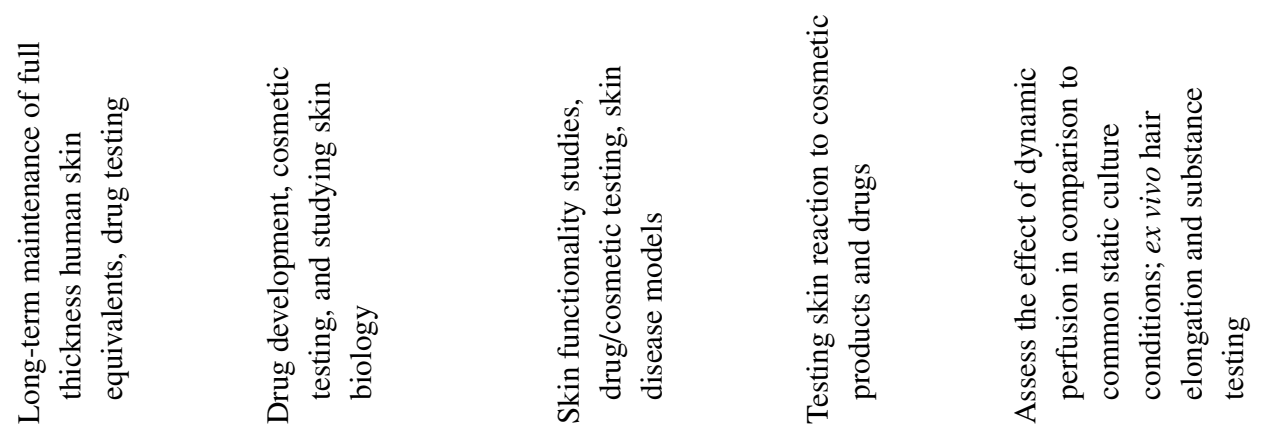

$\underset{\infty}{\widetilde{\infty}}$

$\bar{\infty}$

$\bar{\Xi}$

$\bar{\sigma}$

$\bar{\Xi}$
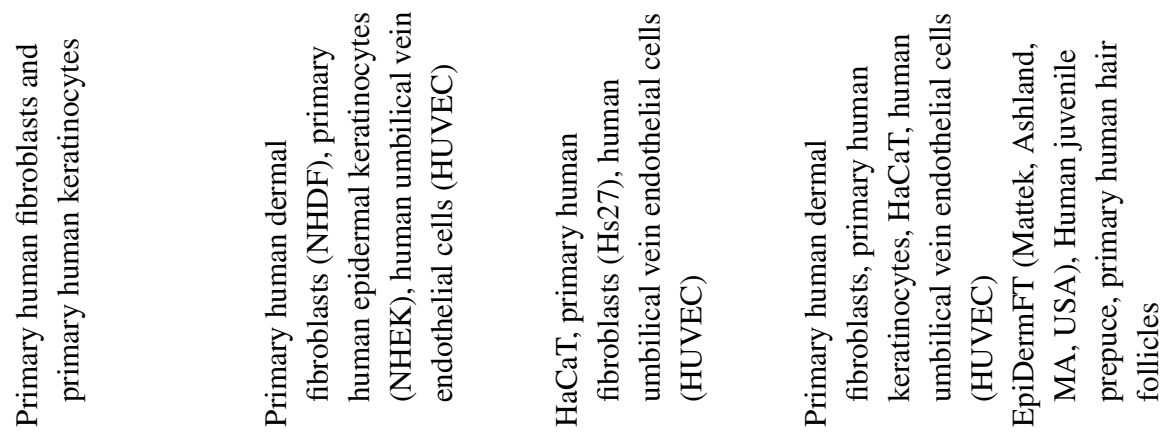

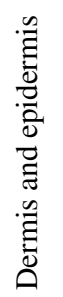

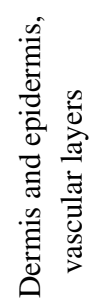

章
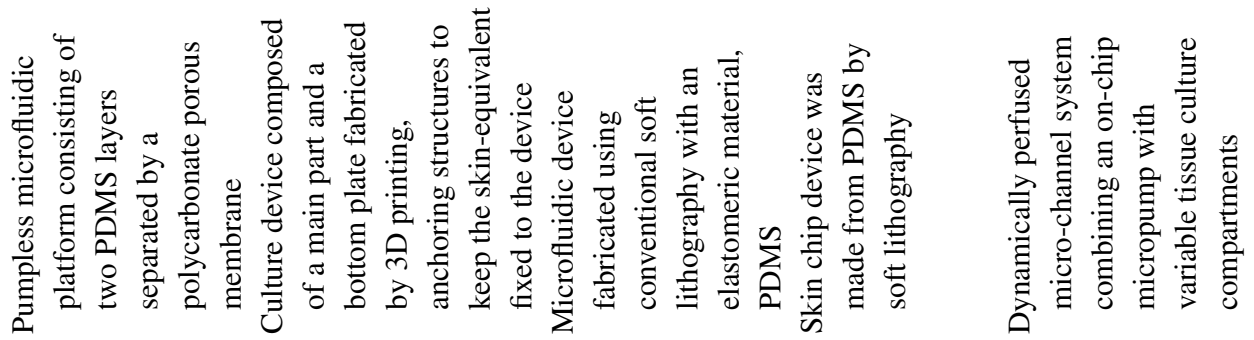


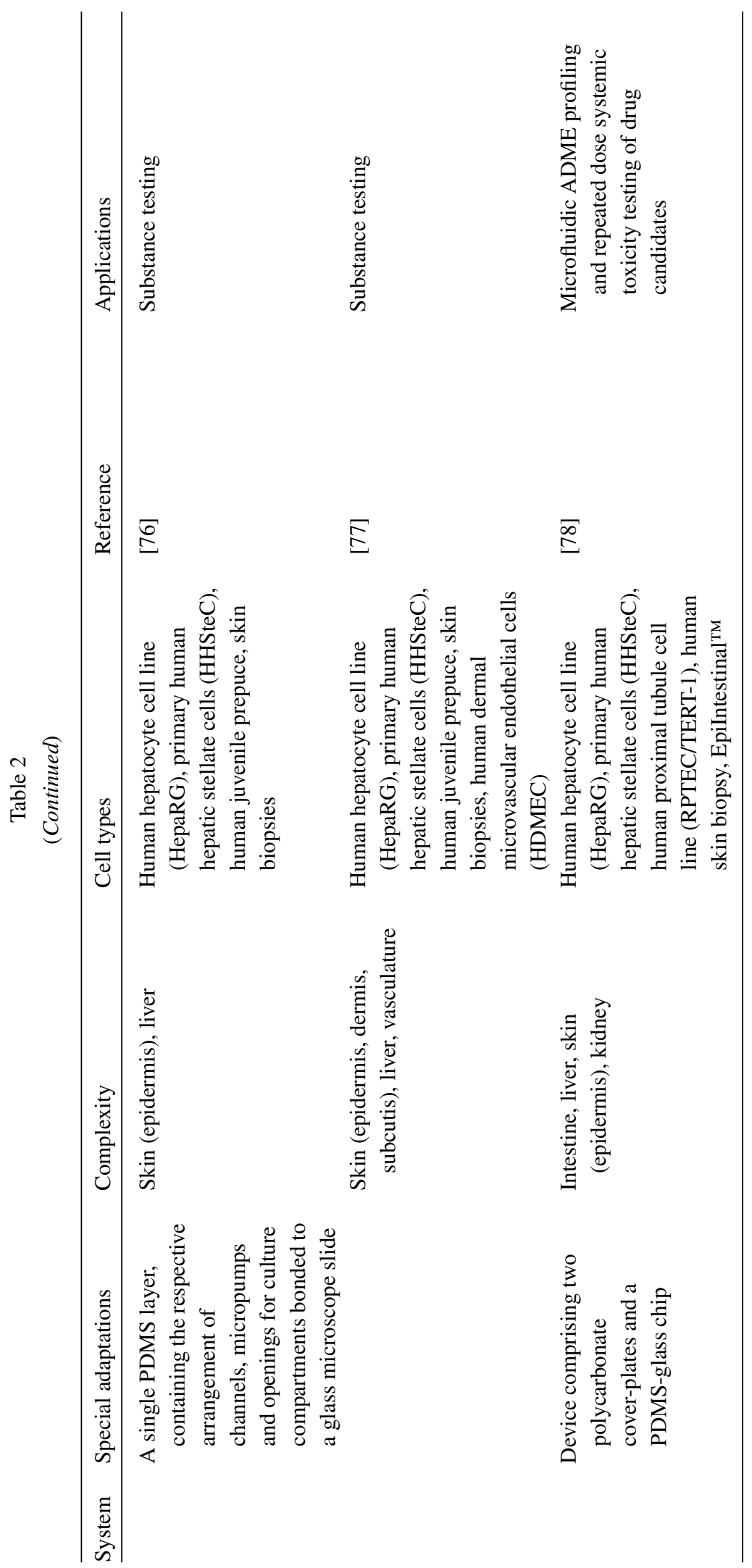




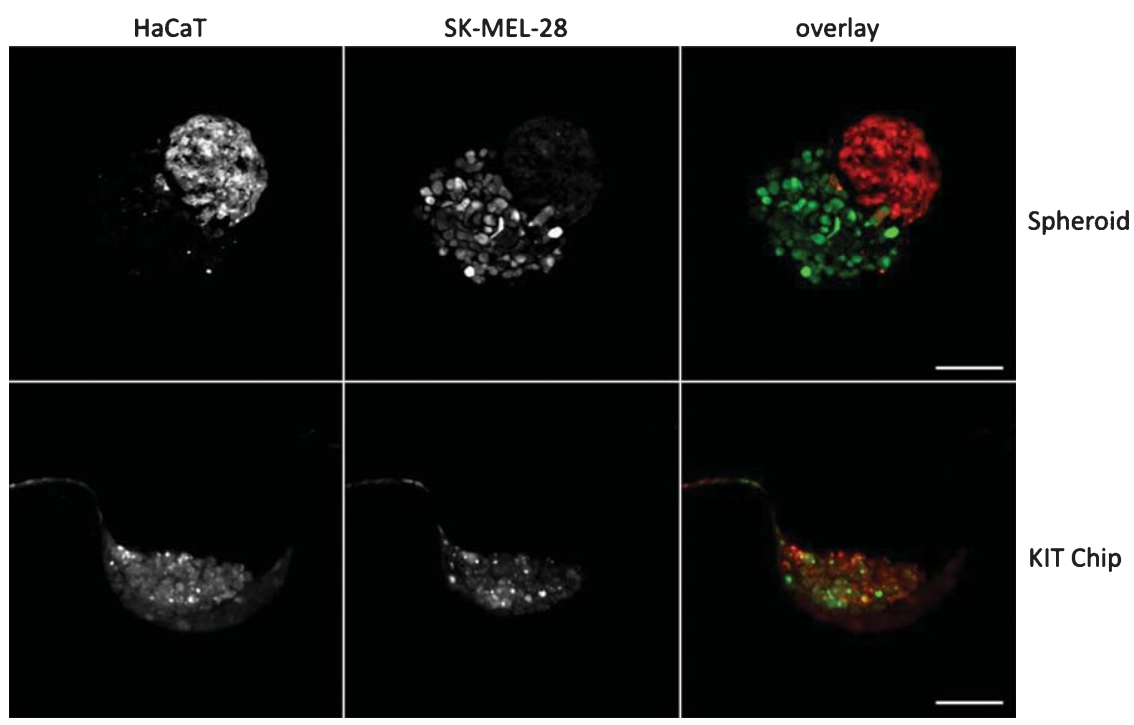

Fig. 3. Co-culture of keratinocytes and melanoma cells. HaCaT and SK-MEL-28 cells were stained with Cell Tracker Red (red in overlays) and Cell Tracker Green (green in overlays), respectively. Then, cells were seeded simultaneously to grow as spheroids and on the KIT Chip. After 7 (spheroids) or 12 days (KIT Chip) in 3D culture, spheroids and KIT Chip were sectioned into $10-\mu \mathrm{m}$ and $30-\mu \mathrm{m}$ thick slices, respectively. KIT Chips were assembled as described previously [106]. Scale bars, $100 \mu \mathrm{m}$.

fibroblasts on the invasion of melanoma using magnetically labelled fibroblasts and melanoma to generate co-culture spheroids [25]. Another melanoma system used HaCaT spheroids as a scaffold for melanoma cells in a bioreactor system [26]. Also, Peura et al. showed the importance of a spheroid network to harvest released factors from the cells to produce an active matrix [27]. However, none of these studies characterized the development of typical epidermal stratification. In our laboratory, $\mathrm{HaCaT}$ spheroids were generated with cell repellent U-bottom shaped plates from Greiner and cultured in growth media (DMEM $+10 \%$ fetal calf serum $+1 \%$ penicillin/streptomycin). The resulting spheroids were immunostained for the differentiation markers KRT14 and KRT10, showing an inner, basal and an outer, differentiated epidermal layer (Fig. 2). Furthermore, we established 3D skinmelanoma in vitro models to gain information about the interaction of keratinocytes and melanoma cells. We show the spatial arrangement of these cells when grown as spheroids or on the KIT Chip. First, cells were stained with Cell Tracker dyes (HaCaT keratinocytes were stained with Cell Tracker Red and SK-MEL-28 melanoma cells with Cell Tracker Green). Both cell types were seeded simultaneously to grow as spheroids or on the KIT Chip. Depending on the 3D culture condition, the cells arranged differently. When grown as spheroids, they formed separate entities with a central HaCaT spheroid and SK-MEL-28 aggregates around the spheroid (Fig. 3A). Conversely, when grown on the KIT Chip, the two cell types were mixing, building a common sheet of keratinocytes and melanoma cells (Fig. 3B).

It still needs to be determined, if skin cell spheroids can be grown to reach complete differentiation and full layer stratification as for standard hydrogel or 3D printing models. First promising results were reported, which describe a spherical skin microtissue (3D InSight(TM) Skin Microtissue, InSphero, Schlieren, Switzerland) composed of different keratinocyte layers and a dermal fibroblast core, which produces exctracellular matrix proteins without the need for exogenous collagen [28]. Spheroids are potentially very interesting systems also for skin research due to their simplicity, low cost and high reproducibility. Hence, they are suitable for high-throughput cell function and cytotoxicity analysis [29]. Most spheroids can be dispersed by lysis buffer or enzymes and therefore, they are also appropriate 
for biochemical analysis [30]. Whole mount microscopic analysis of spheroids can be performed by confocal microscopy [31] or light-sheet microscopy [32], while for conventional microscopy one has to section spheroids prior to imaging [33].

\subsection{Hydrogel systems}

The most dominant technique for creating an in vitro skin model is the use of hydrogels that serve as a scaffold for dermal fibroblasts, which is then co-cultured with keratinocytes on the surface. Collagen I, the leading class of ECM protein, is the typically used hydrogel material, and dermal fibroblast cells are usually distributed within the collagen gel to mimic the dermal layer $[34,35]$. The first hydrogel system using epidermal cells on top of a primary rat fibroblast-seeded collagen scaffold was described by Bell and colleagues [36]. Apart from collagens, also other ECM interacting proteins can be used to generate hydrogels. For example, Alameda et al. generated 3D cultures of HaCaT keratinocytes and fibroblasts in fibrin gels to obtain human skin equivalents that comprise an epidermal and a dermal compartment that resembles both the structure and stratification of normal human skin [37]. Increasing numbers of commercially available skin models, that are based on hydrogels, have reached the market, such as EpiDerm (MatTek, Ashland, MA, USA), Episkin (L'Oreal; SkinEthic, Nice, France), Apligraf (Organogenesis Inc., Canton, MA, USA), and Labskin (Innovenn, Dublin, Ireland).

Using hydrogel systems, one can assemble the dermal layer and the stratified layers of the epidermis. Special protocols of air exposure $[38,39]$ or combinations of high $\mathrm{Ca}^{2+}$ and low temperature [10] induce complete keratinocyte differentiation, including cornification. Its high level of differentiation makes this system a good approach to study effects on specific epidermal layers. Typically applied cell types are primary human dermal fibroblasts and primary keratinocytes [34, 40], but also keratinocyte cell lines like HaCaT cells are used [38]. Simple psoriasis models, which are also commercially available (MatTek Corp., Ashland, MA, USA), are composed of healthy keratinocytes and diseased fibroblasts isolated from psoriatic lesions of patients. However, the use of psoriatic epidermal keratinocytes more closely resembles psoriatic conditions [41].

Depending on the application, all three major skin layers including the subcutis with human adiposederived stem cells and adipocytes can be assembled [42]. To generate a cancer model, melanocytes and/or melanoma cells can be added [43]. Since skin cancer, psoriasis, and other skin diseases involve the complex cross-talk between various cell types and cytokines, 3D skin models that also contain immune cells are of great value. Van den Bogaard et al. were the first, who achieved to generate 3D skin equivalents that included different T-cell populations. It allowed to study migration of immune cells and secretion of proinflammatory cytokines in the context of psoriasis [44]. However, hyperproliferation was not observed and cytokine levels were much lower compared to the in vivo situation, suggesting that crucial components and relevant cell types are still missing to create a more complete psoriasis model.

$3 \mathrm{D}$ in vitro hydrogel systems can be used to evaluate epidermal behaviour, e.g. to address the impact of epimorphin modulation on epidermal growth factor receptor-driven epidermal differentiation in an organotypic skin model [45]. Furthermore, Zanoni and co-workers investigated the cytotoxicity of different chemicals, like hair dyes on a hydrogel-based skin system [35]. The major advantages of hydrogel based models are their defined biomimetic functions. Cell adhesion sites can be varied by the use of peptides like RGD or IKVAV [46, 47]. In addition, the cell-mediated degradability, the low stiffness of the gels as well as the gel material itself can be modified (e.g. collagen, fibrin, gelatin) $[37,45,48]$. Since the cells can be recovered from the gels by proteases hydrogel systems are also convenient for molecular analysis (Western Blot, Polymerase Chain Reaction (PCR)) [40, 43] and their transparency allows microscopy [38]. The costs are moderate. They are cheaper than microfluidic devices but more expensive than simple spheroid systems. Their handling is easy but based on the 
involved biological components the gels might have a high batch-to-batch variability which makes it difficult to repeatedly achieve the same results.

\section{3. $3 D$ bioprinting}

Bioprinting allows the automated generation of complex tissue architectures [49]. Different layers of a desired material, mostly in the forms of hydrogel or biodegradable scaffolds, can be printed to form such geometries. Subsequently, biomolecules or cells can be added to defined positions to form various biological structures of interest [50]. As a pioneer of 3D printing, Charles W. Hull introduced the stereolithography method by uniting thin layers of certain materials with ultraviolet light [51]. Later, the technology was improved leading to new methods, such as laser printing [52] and ink printing [53]. In addition, soft lithographic methods were developed, which utilize 'stamping' of each cell-containing layer by creating layer-specific molds and stacking of these layers to provide a 3D shape [54,55]. These approaches, however, often include complex manufacturing processes containing the spatially accurate location of cell-containing tissue layers.

As 3D bioprinting has the ability to manufacture the 3D structures in an on-demand fashion, it has been applied to create various biomimetic structures, such as fluidic channels [56], vascular-like structures [49], growth-factor releasing matrices [57], 3D neural tissues [58], and tumor cell-bearing tissues for angiogenesis models [59]. With regard to bioprinted skin, complex skin tissues with dermal and epidermal layers containing keratinocytes, melanocytes and fibroblasts were generated [49, 58, 60, 61]. More complete models comprising also subcutis and other structures have not yet been presented.

Using the potential of 3D bioprinting, Lee and colleagues fabricated a biomimetic human skin with a similar morphology to native skin layers, in which keratinocytes and fibroblasts resembled the epidermis and dermis, and collagen the dermal matrix [49]. Using laser-assisted bioprinting to embed keratinocytes and fibroblasts in collagen, Koch and colleagues showed, that the printing process does not harm cells and that cells differentiate and form functional gap- as well as adherent junctions [60].

Modern 3D bioprinting is mostly automated and therefore provides high reproducibility and highthroughput. As the scaffolds can be varied on demand and as different cell types and active molecules can be applied, bioprinting is a highly flexible method. Consequently, this system has potentials in tissue engineering as well as in cytotoxicity testing and pathophysiology of skin diseases [49]. Furthermore, bioprinted tissue can be imaged by fluorescence microscopy and analysed by molecular biology methods like Western Blot and PCR [49, 62]. However, 3D printing is only available in a few laboratories due to its high costs and complex printing system.

\subsection{Organ-on-a-chip}

Organ-on-a-chip technology is the reconstruction of tissue and organs by culturing living cells in a continuously perfused microscale environment with spatiotemporal control [63, 64]. It is here not the goal to form a completely living organ but to create minimal functional units that summarize functions of tissue and organs. The easiest system is a single, perfused microfluidic chamber containing one type of cells that displays functions of one tissue. In more complex designs, two or more microfluidic chambers are connected by porous membranes with different cell types to mimic interfaces between different tissues [64]. The chips are mostly made by a modified form of photolithographic etching. Microfluidic culture systems are often made by 'soft lithography', which is the etching of replicating patterns into silicon chips in more biocompatible and flexible materials. For this, a liquid polymer, such as polydimethylsiloxane (PDMS), is poured on an etched silicon substrate and allowed to polymerize into an optically clear, rubber-like material, basically creating a rubber stamp [65]. While most of the chips are perfused with a pumping system [66], some are pumpless using a rocking platform [67]. 
In comparison to the above described 3D in vitro systems, microfluidic skin-on-a-chip provides the best physiology and functionality. Hence, all systems have a perfusion whereby shear stress is produced which in turn increases cell viability and proliferation in contrast to static cultures [68]. Additionally, almost all systems offer an air-liquid-interface culture [69]. Depending on the application, either skin biopsies, primary cells or cell lines can be used [66, 68, 69]. Also, human induced pluripotent stem cells provide a source to mimic healthy and diseased skin models as they can be differentiated into keratinocytes [70], fibroblasts [71], melanocytes [72] and endothelial cells [67]. Besides simplified models with dermis and epidermis, also more complex models with hair follicles and adipocytes [73], immune cells [74] and features resembling sweat gland pores [75] exist. In addition, skin-on-a-chip can be expanded to multiple organ chips to test drug metabolism. Accordingly, Maschmeyer et al. and Wagner et al. engineered two and four organ chips with intestine, liver, skin and kidney [76-78]. Furthermore, disease models simulating inflammation and edema exist [79].

After Black et al., who generated capillary-like structures in a co-culture of fibroblasts and keratinocytes [80], Groeber and colleagues published the first full thickness skin model with populated vessels that can be physiologically perfused [66]. Groeber's model is based on primary keratinocytes, fibroblasts as well as endothelial cells, which were cultured at the air-liquid-interface on a decellularized biological vascularized scaffold in a bioreactor. After two weeks, they reported the formation of human dermis and epidermis architecture containing repopulated functional vessels [66]. In contrast, Lee and co-workers used a human engineered chip with a chamber for skin cells and microfluidic channels for endothelial culture $[69,81]$ and Abaci et al. achieved vascularization with the use of induced pluripotent stem cells (iPSCs) [82].

The major advantage of the microfluidic chip is the physiological flow of medium through the vascular-like system, which permits a constant oxygen and nutrient supply. This affects cell-cell communications and local concentrations of secreted ligands of tissues [73]. The presence of flow also allows the study of circulating cells, such as circulating breast cancer cells with microvascular endothelium at potential sites of metastasis [83] or immune cells [84]. Using a multi-organ-chip, one can link different organs into a systemic arrangement imitating that of the human organism at a miniaturised scale [76]. Combining the four organ equivalents, skin, intestine, liver, and kidney, this model allows for in vitro microfluidic ADME - absorption, distribution, metabolism and excretion - profiling [78]. Prospectively, iPSCs have the potential to predict patient-specific response to therapies [85]. Accordingly, the chips are the best model to predict efficiency, pharmacokinetics, pharmacodynamics and for screening assays. As the chips are mostly made of PDMS, they allow for in vitro microscopy [77]. However, PDMS has the disadvantage that it might absorb small molecules such as drugs [86]. Molecular analysis, like PCR, is feasible [79]. The main limitations are the high costs of this system and the demanding skills due to its complex assembly. Another point is that arising bubbles can impair biological function and often viability as it increases the wall shear stress in a liquid-perfused microchannel [87, 88].

\subsection{Outlook: Skin organoids and their potential use for personalized approaches}

Organoids can be defined as 3D cell culture models mimicking the organ the cells originated from [89]. More accurately, organoids [i] contain more than one cell type, [ii] show physiological function of the organ they model, and [iii] are formed by self-assembly of cells and show organization of the specific organ $[90,91]$. The present models arose with the introduction of the hanging drop method by Harrison in 1906 [20] and Wilson who showed self-organization of sponge cells forming a whole organism [92]. Since those progenitor models mostly required large numbers of primary cells from organs, high-throughput screening was not feasible and viability was limited [89]. Nowadays, organoids 
are mostly generated from two main types of stem cells: [i] pluripotent embryonic stem (ES) cells and their synthetic iPSCs counterparts and [ii] organ-restricted adult stem cells (aSCs) [93].

To our knowledge, skin organoid models have not been described yet. Nonetheless, it was shown that human iPSC provide a source to mimic healthy skin models as they can be differentiated into keratinocytes [70], fibroblasts [71], melanocytes [72], and endothelial cells [67]. Disease models can be generated with iPSCs derived from somatic cells having a genetic mutation. To mimic keratinocytes in recessive dystrophic epidermolysis bullosa, Itoh et al. isolated cells from diseased patients, reprogrammed them into iPSCs and differentiated them into keratinocytes [94]. Prospectively, iPSCs have the potential to predict patient-specific response to therapies. This is of particular importance since current treatments for psoriasis and other skin disorders are not effective in all patients [41]. Furthermore, it is an unlimited source of cells. However, iPSCs are laborintensive, reprogramming and differentiation are not matured yet, and there are few high-throughput approaches [85].

\section{Declaration of interest}

No competing interests are declared.

\section{Acknowledgments}

This work was funded by the German Federal Ministry of Research (BMBF) as part of the Innovation Partnership $\mathrm{M}^{2}$ Aind, project $\mathrm{M}^{2}$ OGA (03FH8I02IA) within the framework "Starke Fachhochschulen - Impuls für die Region“" (FH-Impuls). This research project is part of the Forschungscampus $\mathrm{M}^{2} \mathrm{OLIE}$ and funded by the German Federal Ministry of Education and Research (BMBF) within the Framework "Forschungscampus: public-private partnership for Innovations".

\section{References}

[1] Breitkreutz D, Mirancea N, Nischt R. Basement membranes in skin: Unique matrix structures with diverse functions? Histochem Cell Biol 2009;132(1):1-10.

[2] Haines RL, Lane EB. Keratins and disease at a glance. J Cell Sci 2012;125(Pt 17):3923-8.

[3] Toivola DM, Boor P, Alam C, Strnad P. Keratins in health and disease. Curr Opin Cell Biol 2015;32:73-81.

[4] Rinnerthaler M, Streubel MK, Bischof J, Richter K. Skin aging, gene expression and calcium. Exp Gerontol 2015;68:59-65.

[5] Fuchs E, Green H. Changes in keratin gene expression during terminal differentiation of the keratinocyte. Cell 1980;19(4):1033-42.

[6] Freedberg I, Tomic-Canic M, Komine M, Blumenberg M. Keratins and the keratinocyte activation cycle. J Invest Dermatol. 2001;116(5):633-40.

[7] Moll R, Divo M, Langbein L. The human keratins: Biology and pathology. Histochem Cell Biol 2008;129(6):705-33.

[8] Candi E, Schmidt R, Melino G. The cornified envelope: A model of cell death in the skin. Nat Rev Mol Cell Biol 2005;6(4):328-40.

[9] Breiden B, Sandhoff K. The role of sphingolipid metabolism in cutaneous permeabilitybarrier formation. Biochim Biophys Acta - Mol Cell Biol Lipids 2014;1841(3):441-52.

[10] Borowiec A-S, Delcourt P, Dewailly E, Bidaux G. Optimal differentiation of in vitro keratinocytes requires multifactorial external control. PLoS One 2013;8(10):e77507.

[11] Nguyen VT, Ndoye A, Hall LL, Zia S, Arredondo J, Chernyavsky AI, et al. Programmed cell death of keratinocytes culminates in apoptotic secretion of a humectant upon secretagogue action of acetylcholine. J Cell Sci 2001;114(Pt 6): 1189-204. 
[12] Kurasawa M, Maeda T, Oba A, Yamamoto T, Sasaki H. Tight junction regulates epidermal calcium ion gradient and differentiation. Biochem Biophys Res Commun 2011;406(4):506-11.

[13] Svoboda M, Bílková Z, Muthný T. Could tight junctions regulate the barrier function of the aged skin? J Dermatol Sci 2016;81(3):147-52.

[14] Krueger JG, Bowcock A. Psoriasis pathophysiology: Current concepts of pathogenesis. Ann Rheum Dis 2005;64(suppl_2):ii30-ii36.

[15] Kim S, Wong P, Coulombe PA. A keratin cytoskeletal protein regulates protein synthesis and epithelial cell growth. Nature 2006;441(7091):362-5.

[16] Chandrasekaran S, Giang U-BT, King MR, DeLouise LA. Microenvironment induced spheroid to sheeting transition of immortalized human keratinocytes $(\mathrm{HaCaT})$ cultured in microbubbles formed in polydimethylsiloxane. Biomaterials 2011;32(29):7159-68.

[17] Halpern B, Pejsachowicz B, Febvre HL, Barski G. Differences in patterns of aggregation of malignant and nonmalignant mammalian cells. Nature 1966;209(5019):157-9.

[18] Inch WR, McCredie JA, Sutherland RM. Growth of nodular carcinomas in rodents compared with multi-cell spheroids in tissue culture. Growth 1970;34(3):271-82.

[19] Aihara E, Mahe MM, Schumacher MA, Matthis AL, Feng R, Ren W, et al. Characterization of stem/progenitor cell cycle using murine circumvallate papilla taste bud organoid. Sci Rep 2015;5(1):17185.

[20] Harrison R. Observations on the living developing nerve fibre. Proc Soc Exp Biol 1907;4:140.

[21] Foty R. A simple hanging drop cell culture protocol for generation of 3D spheroids. J Vis Exp $2011 ; 51$.

[22] Phung YT, Barbone D, Broaddus VC, Ho M. Rapid generation of in vitro multicellular spheroids for the study of monoclonal antibody therapy. J Cancer 2011;2:507-14.

[23] Lin SJ, Jee SH, Hsaio WC, Lee SJ, Young TH. Formation of melanocyte spheroids on the chitosan-coated surface. Biomaterials. 2005;26(12):1413-22.

[24] Marx U. Trends in Cell Culture Technology. In: Advances in experimental medicine and biology 2012. pp. $26-46$.

[25] Okochi M, Matsumura T, Yamamoto S, Nakayama E, Jimbow K, Honda H. Cell behavior observation and gene expression analysis of melanoma associated with stromal fibroblasts in a three-dimensional magnetic cell culture array. Biotechnol Prog 2013;29(1):135-42.

[26] Marrero B, Messina JL, Heller R. Generation of a tumor spheroid in a microgravity environment as a 3D model of melanoma. Vitr Cell Dev Biol - Anim 2009;45(9):523-34.

[27] Peura M, Siltanen A, Saarinen I, Soots A, Bizik J, Vuola J, et al. Paracrine factors from fibroblast aggregates in a fibrin-matrix carrier enhance keratinocyte viability and migration. J Biomed Mater Res - Part A 2010;95 A(2):658-64.

[28] Ströbel S, Buschmann N, Neeladkandhan A, Messner S, Kelm JM. Characterization of a novel in vitro 3D skin microtissue model for efficacy and toxicity testing. In: Toxicology Letters 258S. 2016. S156.

[29] Ivascu A, Kubbies M. Rapid generation of single-tumor spheroids for high-throughput cell function and toxicity analysis. J Biomol Screen 2006;11(8):922-32.

[30] Vörsmann H, Groeber F, Walles H, Busch S, Beissert S, Walczak H, et al. Development of a human three-dimensional organotypic skin-melanoma spheroid model for in vitro drug testing. Cell Death Dis 2013;4(7):e719.

[31] Rebelo SP, Costa R, Estrada M, Shevchenko V, Brito C, Alves PM. HepaRG microencapsulated spheroids in DMSO-free culture: Novel culturing approaches for enhanced xenobiotic and biosynthetic metabolism. Arch Toxicol 2014;89(8):1347-58.

[32] Smyrek I, Stelzer EHK. Quantitative three-dimensional evaluation of immunofluorescence staining for large whole mount spheroids with light sheet microscopy. Biomed Opt Express 2017;8(2):484.

[33] Raleigh JA, Miller GG, Franko AJ, Koch CJ, Fuciarelli AF, Kelly DA. Fluorescence immunohistochemical detection of hypoxic cells in spheroids and tumours. Br J Cancer 1987;56(4):395-400.

[34] Carlson MW, Alt-Holland A, Egles C, Garlick JA. Three-Dimensional Tissue Models of Normal and Diseased Skin. In: Current Protocols in Cell Biology. Hoboken, NJ, USA: John Wiley \& Sons, Inc.; 2008; Unit 19.9.

[35] Zanoni TB, Tiago M, Faião-Flores F, de Moraes Barros SB, Bast A, Hageman G, et al. Basic Red 51, a permitted semi-permanent hair dye, is cytotoxic to human skin cells: Studies in monolayer and 3D skin model using human keratinocytes (HaCaT). Toxicol Lett 2014;227(2):139-49.

[36] Bell E, Ehrlich HP, Buttle DJ, Nakatsuji T. Living tissue formed in vitro and accepted as skin-equivalent tissue of full thickness. Science 1981;211(4486):1052-4.

[37] Alameda JP, Navarro M, Ramírez Á, Page A, Suárez-Cabrera C, Moreno-Maldonado R, et al. IKK $\alpha$ regulates the stratification and differentiation of the epidermis: Implications for skin cancer development. Oncotarget 2016;7(47):76779-92.

[38] Schoop VM, Mirancea N, Fusenig NE. Epidermal organization and differentiation of HaCat keratinocytes in organotypic coculture with human dermal fibroblasts. J Invest Dermatol 1999;112(3):343-53. 
[39] Denda M, Denda S. Air-exposed keratinocytes exhibited intracellular calcium oscillation. Ski Res Technol 2007;13(2):195-201.

[40] Smola H, Thiekotter G, Fusenig NE. Mutual induction of growth factor gene expression by epidermal-dermal cell interaction. J Cell Biol 1993;122(2):417-29.

[41] Soboleva AG, Mezentsev A, Zolotorenko A, Bruskin S, Pirusian E. Three-dimensional skin models of psoriasis. Cells Tissues Organs 2014;199(5-6):301-10.

[42] Kober J, Gugerell A, Schmid M, Kamolz LP, Keck M. Generation of a Fibrin Based Three-Layered Skin Substitute. Biomed Res Int 2015;2015:170427.

[43] Brohem CA, Massaro RR, Tiago M, Marinho E, Jasiulionis MG, Almeida RL De, et al. Artificial skin in perspective: Concepts and applications. Pigment Cell \& Melanoma Res 2011;24(1):35-50.

[44] van den Bogaard EH, Tjabringa GS, Joosten I, Vonk-Bergers M, van Rijssen E, Tijssen HJ, et al. Crosstalk between keratinocytes and $\mathrm{T}$ cells in a 3D microenvironment: A model to study inflammatory skin diseases. J Invest Dermatol 2014;134(3):719-27.

[45] Okugawa Y, Hirai Y. Extracellular epimorphin modulates epidermal differentiation signals mediated by epidermal growth factor receptor. J Dermatol Sci 2013;69(3):236-42.

[46] Hern DL, Hubbell JA. Incorporation of adhesion peptides into nonadhesive hydrogels useful for tissue resurfacing. J Biomed Mater Res 1998;39(2):266-76.

[47] Hosseinkhani H, Hiraoka Y, Li CH, Chen YR, Yu DS, Hong P Da, et al. Engineering three-dimensional collagen-IKVAV matrix to mimic neural microenvironment. ACS Chem Neurosci. 2013;4(8):1229-35.

[48] Zhao X, Lang Q, Yildirimer L, Lin ZY, Cui W, Annabi N, et al. Photocrosslinkable gelatin hydrogel for epidermal tissue engineering. Adv Healthc Mater 2016;5(1):108-18.

[49] Lee V, Singh G, Trasatti JP, Bjornsson C, Xu X, Tran TN, et al. Design and fabrication of human skin by threedimensional bioprinting. Tissue Eng Part C Methods 2014;20(6):473-84.

[50] Yoo S-S. 3D-printed biological organs: Medical potential and patenting opportunity. Expert Opin Ther Pat 2015;25(5):507-11.

[51] Hull CW. Apparatus for production of three-dimensional objects by stereolithography. USA: Hull, C.W.; US4575330 A, 1986.

[52] Barron JA, Wu P, Ladouceur HD, Ringeisen BR. Biological laser printing: A novel technique for creating heterogeneous 3-dimensional cell patterns. Biomed Microdevices 2004;6(2):139-47.

[53] Xu T, Kincaid H, Atala A, Yoo JJ. High-throughput production of single-cell microparticles using an inkjet printing technology. J Manuf Sci Eng 2008;130(2):210171-5.

[54] Lee W, Son J, Yoo S-S, Park J-K. Facile and Biocompatible Fabrication of Chemically Sol-Gel Transitional Hydrogel Free-Standing Microarchitectures. Biomacromolecules. 2011;12:14-8.

[55] Son J, Bae CY, Park JK. Freestanding stacked mesh-like hydrogel sheets enable the creation of complex macroscale cellular scaffolds. Biotechnol J 2016;11(4):585-91.

[56] Lee W, Lee V, Polio S, Keegan P, Lee JH, Fischer K, et al. On-demand three-dimensional freeform fabrication of multi-layered hydrogel scaffold with fluidic channels. Biotechnol Bioeng 2010;105(6):1178-86.

[57] Lee YB, Polio S, Lee W, Dai G, Menon L, Carroll RS, et al. Bio-printing of collagen and VEGF-releasing fibrin gel scaffolds for neural stem cell culture. Exp Neurol 2010;223(2):645-52.

[58] Lee W, Debasitis JC, Lee VK, Lee J-H, Fischer K, Edminster K, et al. Multi-layered culture of human skin fibroblasts and keratinocytes through three-dimensional freeform fabrication. Biomaterials 2009;30(8):1587-95.

[59] Lee VK, Dai G, Zou H, Yoo SS. Generation of 3-D glioblastoma-vascular niche using 3-D bioprinting. 41st Annu Northeast Biomed Eng Conf NEBEC 2015 2015;3-4.

[60] Koch L, Deiwick A, Schlie S, Michael S, Gruene M, Coger V, et al. Skin tissue generation by laser cell printing. Biotechnol Bioeng 2012;109(7):1855-63.

[61] Min D, Lee W, Bae I-H, Lee TR, Croce P, Yoo S-S. Bioprinting of Biomimetic Skin containing Melanocytes. Exp Dermatol 2017; Available from: http://www.ncbi.nlm.nih.gov/pubmed/28453913

[62] Wang X-F, Song Y, Liu Y-S, Sun Y, Wang Y, Wang Y, et al. Osteogenic differentiation of three-dimensional bioprinted constructs consisting of human adipose-derived stem cells in vitro and in vivo. PLoS One 2016;11(6):e0157214.

[63] Sung JH, Esch MB, Prot J-M, Long CJ, Smith A, Hickman JJ, et al. Microfabricated mammalian organ systems and their integration into models of whole animals and humans. Lab Chip 2013;13(7):1201.

[64] Bhatia SN, Ingber DE. Microfluidic organs-on-chips. Nat Biotechnol 2014;32(8):760-72.

[65] Duffy DC, McDonald JC, Schueller OJA, Whitesides GM. Rapid prototyping of microfluidic systems in poly (dimethylsiloxane). Anal Chem 1998;70(23):4974-84.

[66] Groeber F, Engelhardt L, Lange J, Kurdyn S, Schmid FF, Rucker C, et al. A first vascularized skin equivalent as an alternative to animal experimentation. ALTEX 2016;33(4):415-22. 
[67] Abaci HE, Guo Z, Coffman A, Gillette B, Lee WH, Sia SK, et al. Human skin constructs with spatially controlled vasculature using primary and iPSC-derived endothelial cells. Adv Healthc Mater 2016;5(14):1800-7.

[68] O'Neill AT, Monteiro-Riviere NA, Walker GM. Characterization of microfluidic human epidermal keratinocyte culture. Cytotechnology 2008;56(3):197-207.

[69] Lee S, Jin S-P, Kim YK, Sung GY, Chung JH, Sung JH. Construction of 3D multicellular microfluidic chip for an in vitro skin model. Biomed Microdevices 2017;19(2):22.

[70] Kogut I, Roop DR, Bilousova G. Differentiation of Human Induced Pluripotent Stem Cells into a Keratinocyte Lineage. In: Methods in molecular biology (Clifton, NJ) 2013. pp. 1-12.

[71] Hewitt KJ, Shamis Y, Hayman RB, Margvelashvili M, Dong S, Carlson MW, et al. Epigenetic and phenotypic profile of fibroblasts derived from induced pluripotent stem cells. PLoS One 2011;6(2).

[72] Ohta S, Imaizumi Y, Okada Y, Akamatsu W, Kuwahara R, Ohyama M, et al. Generation of human melanocytes from induced pluripotent stem cells. PLoS One 2011;6(1):1-10.

[73] Ataç B, Wagner I, Horland R, Lauster R, Marx U, Tonevitsky AG, et al. Skin and hair on-a-chip: In vitro skin models versus ex vivo tissue maintenance with dynamic perfusion. Lab Chip 2013;13(18):3555.

[74] Ramadan Q, Ting FCW. In vitro micro-physiological immune-competent model of the human skin. Lab Chip Royal Society of Chemistry 2016;16(10):1899-908.

[75] Hou L, Hagen J, Wang X, Papautsky I, Naik R, Kelley-Loughnane N, et al. Artificial microfluidic skin for in vitro perspiration simulation and testing. Lab Chip 2013;13(10):1868.

[76] Wagner I, Materne E-M, Brincker S, Süßbier U, Frädrich C, Busek M, et al. A dynamic multi-organ-chip for long-term cultivation and substance testing proven by 3D human liver and skin tissue co-culture. Lab Chip 2013;13(18):3538.

[77] Maschmeyer I, Hasenberg T, Jaenicke A, Lindner M, Lorenz AK, Zech J, et al. Chip-based human liver-intestine and liver-skin co-cultures - A first step toward systemic repeated dose substance testing in vitro. Eur J Pharm Biopharm 2015;95:77-87.

[78] Maschmeyer I, Lorenz AK, Schimek K, Hasenberg T, Ramme AP, Hübner J, et al. A four-organ-chip for interconnected long-term co-culture of human intestine, liver, skin and kidney equivalents. Lab Chip 2015;15(12):2688-99.

[79] Wufuer M, Lee G, Hur W, Jeon B, Kim BJ, Choi TH, et al. Skin-on-a-chip model simulating inflammation, edema and drug-based treatment. Sci Rep 2016;6(1):37471.

[80] Black AF, Hudon V, Damour O, Germain L, Auger FA. A novel approach for studying angiogenesis: A human skin equivalent with a capillary-like network. Cell Biol Toxicol 1999;15(2):81-90.

[81] Mori N, Morimoto Y, Takeuchi S. Skin integrated with perfusable vascular channels on a chip. Biomaterials 2017;116:48-56.

[82] Abaci HE, Gledhill K, Guo Z, Christiano AM, Shuler ML. Pumpless microfluidic platform for drug testing on human skin equivalents. Lab Chip 2015;15(3):882-8.

[83] Song JW, Cavnar SP, Walker AC, Luker KE, Gupta M, Tung YC, et al. Microfluidic endothelium for studying the intravascular adhesion of metastatic breast cancer cells. PLoS One 2009;4(6).

[84] Huh D, Matthews BD, Mammoto A, Montoya-Zavala M, Hsin HY, Ingber DE. Reconstituting organ-level lung functions on a chip. Science 2010;328(5986):1662-8.

[85] van den Broek LJ, Bergers LIJC, Reijnders CMA, Gibbs S. Progress and Future Prospectives in Skin-on-Chip Development with Emphasis on the use of Different Cell Types and Technical Challenges. Stem Cell Rev Reports 2017;13(3):418-428.

[86] van Meer BJ, de Vries H, Firth KSA, van Weerd J, Tertoolen LGJ, Karperien HBJ, et al. Small molecule absorption by PDMS in the context of drug response bioassays. Biochem Biophys Res Commun 2017;482(2):323-8.

[87] Sung JH, Shuler ML. Prevention of air bubble formation in a microfluidic perfusion cell culture system using a microscale bubble trap. Biomed Microdevices. 2009;11(4):731-8.

[88] Lochovsky C, Yasotharan S, Günther A. Bubbles no more: In-plane trapping and removal of bubbles in microfluidic devices. Lab Chip 2012;12(3):595-601.

[89] Hynds RE, Giangreco A. Concise Review: The Relevance of Human Stem Cell-Derived Organoid Models for Epithelial Translational Medicine. Stem Cells 2013;31(3):417-22.

[90] Lancaster MA, Knoblich JA. Generation of cerebral organoids from human pluripotent stem cells. Nat Protoc 2014;9(10):2329-40.

[91] Nadkarni RR, Abed S, Draper JS. Organoids as a model system for studying human lung development and disease. Biochem Biophys Res Commun 2016;473(3):675-82.

[92] Wilson HV. A new method by which sponges may be artificially reared. Science 1907;25(649):912-5.

[93] Clevers H. Modeling Development and Disease with Organoids. Cell 2016;165(7):1586-97.

[94] Itoh M, Kiuru M, Cairo MS, Christiano AM. Generation of keratinocytes from normal and recessive dystrophic epidermolysis bullosa-induced pluripotent stem cells. Proc Natl Acad Sci 2011;108(21):8797-802. 
[95] Woodcock-Mitchell J, Eichner R, Nelson WG, Sun TT. Immunolocalization of keratin polypeptides in human epidermis using monoclonal antibodies. J Cell Biol 1982;95(2 Pt 1):580-8.

[96] Rice RH, Green H. Presence in human epidermal cells of a soluble protein precursor of the cross-linked envelope: Activation of the cross-linking by calcium ions. Cell 1979;18(3):681-94.

[97] Mehrel T, Hohl D, Rothnagel JA, Longley MA, Bundman D, Cheng C, et al. Identification of a major keratinocyte cell envelope protein, loricrin. Cell 1990;61(6):1103-12.

[98] Dale BA, Resing KA, Lonsdale-Eccles JD. Filaggrin: A keratin filament associated protein. Ann N Y Acad Sci 1985;455:330-42.

[99] McLean WHI. Filaggrin failure - from ichthyosis vulgaris to atopic eczema and beyond. Br J Dermatol 2016;175:4-7.

[100] Scholzen T, Gerdes J. The Ki-67 protein: From the known and the unknown. J Cell Physiol 2000;182(3):311-22.

[101] Juriková M, Danihel L, Polák Š, Varga I. Ki67, PCNA, and MCM proteins: Markers of proliferation in the diagnosis of breast cancer. Acta Histochem 2016;118(5):544-52.

[102] Purba TS, Brunken L, Hawkshaw NJ, Peake M, Hardman J, Paus R. A primer for studying cell cycle dynamics of the human hair follicle. Exp Dermatol 2016;25(9):663-8.

[103] Tewari M, Quan LT, O'Rourke K, Desnoyers S, Zeng Z, Beidler DR, et al. Yama/CPP32 beta, a mammalian homolog of CED-3, is a CrmA-inhibitable protease that cleaves the death substrate poly(ADP-ribose) polymerase. Cell 1995;81(5):801-9.

[104] Shalini S, Dorstyn L, Dawar S, Kumar S. Old, new and emerging functions of caspases. Cell Death Differ 2015;22(4):526-39.

[105] Julien O, Wells JA. Caspases and their substrates. Cell Death Differ 2017; Available from: http://www.ncbi.nlm.nih. gov/pubmed/28498362

[106] Altmann B, Giselbrecht S, Weibezahn K-F, Welle A, Gottwald E. The three-dimensional cultivation of the carcinoma cell line HepG2 in a perfused chip system leads to a more differentiated phenotype of the cells compared to monolayer culture. Biomed Mater 2008;3(3):34120. 